\title{
From learning contexts to learning lives: Studying learning (dis)continuities from the perspective of the learners
}

\author{
Alfredo Jornet \\ a.g.jornet@iped.uio.no \\ University of Oslo \\ Ola Erstad \\ ola.erstad@iped.uio.no \\ University of Oslo
}

\begin{abstract}
As digital technologies continue transforming the time and space boundaries that traditionally had been ascribed to different educational settings, the very notion of learning context also is being challenged in educational research literature. In this article, we contribute to this debate by offering an empirically grounded discussion on the contrast between customary notions of context-which emphasize self-containment-and the emerging notion of learning lives-which aims to capture the dialectical relation between continuity and transformation that characterizes life processes. We draw from empirical materials collected through a participant ethnography at an arts-based, communityoriented primary school, where we follow the learning lives of school community members as they participate in a theater project, moving between the school and the home settings. Our analyses compare conceptualizations and analytical categories that emphasize "context" and the associated "boundaries" with conceptualizations and units of analysis that emphasize the fluid and boundless character of learning and living across settings and time.
\end{abstract}

\section{Keywords}

Learning lives, Context, Arts-based Education, Creativity 


\section{Introduction}

If we had to choose a term that would best characterize the socio-cultural and discursive turn that has taken place in educational and learning research during the last four decades, the notion of (cultural) context would certainly be an appropriate choice. Most if not all researchers today agree that the (social, cultural, material) context needs to be accounted for as being part of the equation of learning. It is widely accepted that "all human behavior must be understood relationally, in relation to 'its context' (Cole, 1996, p. 131). Yet, what this precisely means in methodological and analytical terms "has been a source of continuing disagreement and confusion" (p. 131). The situation is more complex today, as the growing prevalence of digital technologies continues transforming the time and space boundaries that traditionally have been ascribed to different educational settings (Kumpulainen \& Sefton-Green, 2014). The very usefulness of the notion context as analytical category is being challenged. As a recent volume puts it, "the question emerges about how we understand a learning context, when the learning is not necessarily bound by a specific set of institutional relationships and structures" (Edwards, 2009, p. 2).

In the latter volume, the question, "life as a learning context?" is raised in an attempt to emphasize the cross-contextual nature of learning in today's (Western) societies and to challenge views of context as container, suggesting instead an inquiry into the myriad of learning opportunities that everyday life opens. Yet, many of the notions that have been developed for that purpose continue to put the emphasis on the self-containment of contexts, focusing, for example, on cultural boundaries and the learners' crossings thereof (Akkerman \& Bakker, 2011). Less often do we find discussions of what a context may be in the terms that would be proper to characterize life's processes, of how the transversal and fluid aspects that characterize being alive (Ingold, 2011) may inform learning research and practice when what we face is an unbounded learning landscape. What type of insights and research opportunities do become available with a discourse that shifts the focus away from bounded contexts and crossings thereof, and which takes the perspective of the learner for whom the ever-unfolding horizon of life continuously opens ahead?

In this article, we address the question above by building upon and expanding recent ideas connected to the notion of learning lives (Erstad, 2012, 2013) and to efforts to theorize (creative) learning activity through a fluid ontology, which aims to "retain the inherently dynamic qualities of life: liquids, fluids, lines, and continuities" (Roth \& Jornet, 2018, p. 39). This involves revisiting the program that was instituted in pioneering anthropological ethnographies of learning, which set to investigate the dialectical relation between "the constitutive order and the experienced world" (Lave, 1988, p. 187), and exploring which type of insights becomes available when the idea of context is supplanted for the idea of (human, cultural) life. We begin reviewing literature discussing the relevance of and shifting interest towards the notion of context in past and present learning research literature. We show how the idea of context as "that which surrounds" (Cole, 1996, p. 6) is still prevalent, even when the aim is to overcome the shortcomings of that very idea. We then move from learning contexts to learning lives, reviewing a number of analytical developments that allow us discussing learning and moving across settings not in terms of things and boundariesthat is, not in terms of an ontology of things-but in terms of life processes-an ontology of life. We ground our theoretical argument in empirical materials collected through a research project aimed at investigating creative and artistic media production across formal and informal learning settings, and which uses participant ethnographic methodologies that allow tracing learners' experiences across multiple settings and time. 


\section{Setting the Problem, or the Problem of Setting}

It is the great achievement of situative and sociocultural approaches to have postulated "the study of cognition as situated action occurring in context" (Cole, 2003, p. 6), so that otherwise abstract and intellectualized aspects of learning such as motivation are now studied from "person-in-context perspectives" (Turner \& Patrick, 2004, p. 1764) using "persons-acting-in-setting" as the unit of analysis (Lave, 1988, p. 189). Support for these approaches comes from research showing how the operations and learners' orientations involved in solving mathematical problems of arithmetic (Lave, 1988) or of geometry (Roth, 2014) in such different settings as classrooms, supermarkets, or the workplace, look very different depending on the setting. Knowing, thus, appears to be not just incidentally but inherently connected to the locations and occasions of use, to the local practices that characterize distinct settings.

A notorious consequence concerns the classical problem of learning transfer. According to the latter, the way people go about learning is by abstracting, from a given setting and occasion, only those features that are relevant and generalizable to a given knowledge domain, leading to more or less generalizable knowledge structures or representations. The acquired knowledge may then be used in future analog (structurally equivalent) situations (for a review, see Reed, 2012). By contrast, emerging situative and sociocultural studies have shown that, in fact, there is considerable situated and material work that goes into structuring new settings/occasions as being adequate for the "application"1 of skills or knowledge learned in other settings/occasions (Jornet, Roth, \& Krange, 2016). Structure-which is but the cognitivist way of saying relevance-is not something researchers or educators can prescribe or assign to given settings, but is generated in situ, in and through situated practice. Situated learning is improvisational (Lave \& Wenger, 1991), it finds resource not in previously formed schemas or knowledge structures in the mind but in the actual situations at hand.

Whereas in most everyday and research parlance context tends to be treated as a container-like space "into which other things are placed" (McDermott, 1993, p. 282), the sociocultural and situative definition above implies a context that is not container-like but that rather is a generative force, which nonetheless exists nowhere else than in and as concrete social and material occasions and locations. The quandary is not only conceptually challenging-as multiple articles and special issues dedicated to the question testify (Greeno, 1997; Sfard, 1998)-but becomes particularly acute in the light of present societal and cultural developments related to the increasing pervasiveness of digital technologies, which have made possible new forms of presence and mobility, transforming and transgressing the "boundaries" that traditionally had been ascribed to learning and education (Erstad, 2013). A danger is that "an emphasis on context can reinforce the idea that learning is bounded in a single time and place" (Bronkhorst \& Akkerman, 2016, p. 19).

To address this issue, researchers have developed and continue developing analytical technologies to better understand today's dynamic processes of learning across settings, while still holding the premise that learning is inherently situated. One of the earliest contributions is the notion of trajectories of participation, where learning no longer is seen as a process of acquiring some knowledge that can be carried over in your head, but rather as a process of becoming a legitimate member in and throughout different forms of practice (Lave \& Wenger, 1991). The notion of consequential transitions has been further developed to characterize how relations between persons and their social contexts change as people move across forms of activity and throughout

\footnotetext{
${ }^{1}$ Here we use the term "application" in quotation marks because, as the cited study shows, the term is indeed a misnomer: even when learners may be said by a knowledgeable observer to be "applying" something they already know, it is most often possible to observe development and change in the very process.
} 
different phases in life (Beach, 1999). Focusing on the work that members perform to establish space and time relations in learning, the notion of chronotope has more recently been advanced to denote "space-time configurations" that are "socially constructed" in situ and which characterize distinct and emergent learning practices (Kumpulainen, Mikkola, \& Jaatinen, 2014, p. 56).

A particularly influential view emphasizes the notion of boundaries,

"all learning involves boundaries. Whether we speak of learning as the change from novice to expert in a particular domain or as the development from legitimate peripheral participation to being a full member of a particular community..., the boundary of the domain or community is constitutive of what counts as expertise or as central participation. When we consider learning in terms of identity development, a key question is the distinction between what is part of me versus what is not (yet) part of me" (Akkerman \& Bakker, 2011, p. 2011).

From this perspective, the boundaries that separate settings, communities, or identities are not simply given and fixed but are themselves seen as processes of interaction and change, where learners work out, jointly with one another, aspects of knowledgeability, membership, identity, and transitions thereof.

The research just reviewed brings us back to the realm of actual everyday, social and material practice. If in classical cognitivist and constructivist approaches the achievement of continuity and discontinuity had ultimately been attributed to abstract mental structures, the situative and sociocultural studies cited above argue that continuity is in fact a practical, social and material achievement. Yet, and paradoxically, the vocabulary and imaginary mobilized-often emphasizing boundaries and crossings thereof (e.g., Tuomi-Gröhn \& Engeström, 2003)-tends to reify the idea of context as contained setting or space-and by the same token of culture, of social relations, and of the environment as "that which surrounds" (Cole, 1996, p. 6), something external (context) against which the person (text) is made to appear as foreground. This in spite of the fact that the situative view demands conceptualizing culture, that is, context, as force that generates both settings and persons. For, unless we take the perspective of the learner (teacher, student) for whom learning is a situated and improvisational (rather than prescribed) activity, the question always remains - to paraphrase Schegloff (1997)-whose context? And whose boundary? If culture, and especially digital culture, "already constitutes a mêlée of sociocultural practices and spaces that are continually hybridized into now forms of practices and spaces" (Roth, 2014, p. 178), is the notion of boundary and its associated ontology able to capture all there is to learning in and across settings?

Our goal is to build upon and contribute to the research cited above by further exploring which research opportunities may be opened by expanding notions of context. If language and communicating shape the type of world we can see and conceive (Vygotsky, 1987), it seems worth exploring other ways of languaging the problem and its solutions. Rather than boundaries, for example, we may want to speak of boundaring ${ }^{2}$. This would involve shifting the focus away from self-contained contexts and self-contained individuals, and instead begin to actually attend to their relation as irreducible to one or the other; it would involve a shift away from a transitive ontology of subjects-verbs-and-objects (as is in "the child crosses the boundary") into an intransitive one, where primacy is given to the joint process of growing-another intransitive verbal form ${ }^{3}$. Such a

\footnotetext{
${ }^{2}$ We are indebted to our colleague Christoph Richter (University of Kiel), in conversations with whom the idea of using the verb "boundaring" emerged.

3 The idea of addressing social processes of growth intransitively has been first suggested in an anthropology of making (Ingold, 2013) and has proven useful in the study of social dimensions of design collaboration (Jornet $\&$ Roth, 2018).
} 
shift, we argue, would bring us closer to an understanding of learning across settings as it unfolds from the perspective of the learners, for it involves a look at learning from the inside. As anthropologist Tim Ingold (2015) poses it, "a world of life" can be looked at "either from the outside, considering every organism as the living embodiment of an evolved design, or from the inside, by joining with the generative movement of its growth and formation-that is, of its coming into being or ontogenesis" (p. 126). It is to take a perspective from the inside that we propose further exploring and expanding the notion learning lives. We ask, what analytical categories may be consistent with an approach that takes life processes rather than settings or contexts as the starting point? What types of insights may using those categories lead to? And how may these insights complement or expand existing situative and sociocultural literature?

\section{From Contexts to Lives}

The notion learning lives emerges as part of an interest in understanding the ways in which digital technologies come to form part and transform the longer pathways of meaning making in the lives of particular individuals (Erstad, 2013). It loosely builds on initial ideas of trajectories of participation (Lave and Wenger, 1991) as well as upon the larger literature-reviewed aboveconcerned with understanding the ways in which settings, technologies, and the learners' everyday practices intertwine across ecologies of learning (Barron, 2004). Distinguishing it is an effort to take the perspective of the learners, rather than that of the sanctioning values and expectations that tend to be ascribed to the (e.g., school) institutions as part of which they learn/grow. Recently, analytical implications of the notion of learning lives have been discussed in literature on learning, media, and technology (Sefton-Green \& Erstad, 2017). Rather than meant to be a final stage or research synthesis, learning lives was first conceived with an imaginative function (Erstad, 2013, p. 3). It is in this later spirit that we take the notion up to further explore its implications and possible programmatic paths.

We also draw on developments in learning and creativity research characterizing design and creative work from the perspective of a fluid- (as opposed to a solid- or object-) ontology (Jornet \& Roth, 2018; Roth \& Jornet, 2018). In these works, the notion of life has been instrumental for the formulation of analytical insights and methodologies aiming at understanding creative development over time and across settings. Crucial to these works has been a reformulation of the notion of context in terms of an unfolding contexture as part of which persons and materials change in mutually constitutive relation (Jornet \& Roth, 2018). This definition is in line with previous descriptions of context as rope, where "the fibers that make up the rope are discontinuous; when you twist them together, you don't make them continuous, you make the thread continuous" (Birdwhistell, in McDermott, 1980, p.4). In this conception, there is not a context-i.e., a culture, a setting, a social environment-and then a person or persons, and their relation. Instead, in a contexture (e.g., a rope) there is an ensemble of threads, where everything that can be discerned as forming part of a context-persons, materials-gets intertwined in such a way so as to build up particular lives, identities, and histories.

This initially abstract characterization has however very concrete implications for the way learning can be approached and followed along trajectories of participation. For, whenever the notion of context, setting, or boundary is brought to bear in analyses of learning, a risk emerges that we may be taking as point of departure divisions that have relevancy based on the prejudices of the researchers, rather than being actually relevant for and thereby constitutive of the learning trajectories being investigated. 
In the remainder of this paper, we set to exhibit, in actual analyses of empirical materials, what kind of analytical categories may be mobilized and which sort of insights may be disclosed when learning lives are attended to from the inside, that is, from the forward perspective of growth as learners move in and through different settings and occasions. Through our analyses, we shall show how, when seen from the forward-looking perspective of life-unfolding events, problems of context are dealt with continuously and always remain open. We are then faced not with a world of contexts and borders, but with an unbounded life that has constrains and forms of organizing of its own, accruing to learning habits and identities. Importantly, humans not only grow but also are makers of the conditions of their own growth. They need to cultivate-which is the sense the word culture takes when used as a verb and not as noun-their own conditions of growth. From a learning lives perspective, then, the task becomes accounting for how the materials of particular biographies-situations, events, experiences-organize themselves so as to be possibly told and recognized as learning stories and biographies not as a function of crossing contexts, but precisely because of their forming part of social life and therefore of history as it grows forward in and through ever-expanding forms of practice.

\section{Methods}

To empirically ground our discussion, in the remainder of this paper we draw from empirical materials collected as part of participant ethnography at (and around) an arts-based primary school in which creative production of art and media plays a central role. The methodology chosen exhibits a commitment with biographical and case-based methodologies aimed at capturing how learning lives unfold as learners grow into inherently hybrid, multicultural teaching and learning practices in and outside of the school. This is chosen so as to be able to offer insights not only concerning the ways academic learning spills outside of the school, traversing across the many settings of everyday life, but also on the different ways in which academic learning itself is transforming in an unbounded and digitalized learning landscape.

\section{a. A learning trajectory in and outside an arts-based school community}

The data-base from which the present study draws is part of a multi-data project aimed at understanding the different ways in which hands-on, artistic and creative multi-media activities contribute to the development and transformation of domain-relevant (science, math, design) skill. The materials mobilized for this study in particular were collected through a one-year long participant ethnography at a small arts-based elementary school in an urban area in Western Canada. The school is representative of a larger trend in current schooling practices, which "are increasingly developing an outward orientation, seeking to connect to students' out-of-school participations" (Bronkhorst \& Akkerman, 2016, p. 18). The participant ethnography was motivated by an interest in better understanding the challenges and opportunities that emerge as school communities work out ways to innovate and implement innovative curricula, in this case using the arts as model and inspiration.

The entire school community participated in the study, including 3 participant researchers who also worked as teacher assistants, 11 teaching and administration staff, and 48 students between 5-12 years old. Most of the school's everyday activities throughout the 2016 - 2017 school year were documented through ethnographic methods, resulting in multitude of ethnographic notes, several hundreds of pictures, and 380 hours of video recordings captured through up to 5 cameras ( 1 high 
definition and 4 wide-angle action cameras) simultaneously filming different angles and aspects of the school activities inside and outside of the school's premises. The materials document numerous learning trajectories and life stories that together, in and through the doings and undergoings of everyday praxis-constitute the struggle and history of an innovative school's community that spans well beyond any distinguishable boundary.

\section{b. Analyses}

Our analyses build from interaction analysis (Jordan \& Henderson, 1995) as well as biographical case story techniques (e.g., Roth \& Erstad, 2016). Learning trajectories were identified and first described by means of thematic categories, thereby identifying and characterizing events that could be examined as forming part coherent collective trajectories of participation. In the present study, we chose one such trajectory: the collective preparations of a performance show as these unfolded throughout several weeks. Conversation analysis techniques were then deployed to examine the moment-to-moment unfolding of specific episodes, which further allowed identifying and pursuing particular learning trajectories. An analytical requisite has been that of ethnographic adequacy, that is, the requisite that the analyst's "account of what natives do together must follow from the way in which the natives structure a situation to allow their participation with each other from one moment to the next" (McDermott, Gospodinoff, \& Aron, 1978, p. 246). The latter requisite is crucial for a perspective aimed at understanding learning lives in their own terms, which means avoiding the assumption that given boundaries will be found in given settings, and embracing the idea that contexts of practice are better described as unfolding, mutually constitutive contextures of people and materials.

\section{Becoming Frida Kahlo: A Forward Reading of a Learning Trajectory}

To empirically ground a learning lives perspective, and to exhibit its possibilities and challenges, in the following sections we present and analyze a trajectory of participation in which a 6-years old student, Carla, takes part in a school-wide project-based preparation of a theater show called "The Masters." The school project includes not only students but also teachers and families, who collaborate in creating the show's script, as part of which Carla ends up playing the role of Frida Kahlo. In our analyses, we follow Carla moving across the school and the home, partly supported by the ubiquitous presence of digital technology, a movement throughout which an initial abstract notion of "master" becomes increasingly concrete and enmeshed in Carla's learning life as she grows further in her role of Frida.

In our analyses, we attempt to produce descriptions in which we take the perspective of the learners, for whom, in the moment-to-moment of everyday life experience, there never can be absolute certainty about what comes next (Roth \& Jornet, 2014). From this perspective, the notion of context-in the classical sense of "that which surrounds"-can only be invoked as an explanatory concept retrospectively, that is, after the fact, once the participants have gone through some segment of activity that later on can be pointed out at as having involved this or that type of situation. Assigning a context to an event or situation, therefore, is a sort of backward reading, and is always debatable. By contrast, living is always a forward and genuinely particular affair. For it is not location or setting but history what adequately describes the way events that have happened before lead to the events that follow. Taking a learning lives perspective means precisely then to read life histories not backwards, but forward, from the first-time-through perspective of the learners. Applying this perspective to the learning trajectory presented below, we show how 
learning events across settings and time weave together a history of development in which experiences in and outside of the school become entangled together, integrating into learning habits and identities that are enacted not only retrospectively, as an achievement (e.g., in terms of self-assessments) but also prospectively in terms of characteristic orientations towards the present, the future, and towards others and the self.

\section{a. Episode 1: Introducing "The Masters"}

We begin our description at one of Carla's school's assemblies, taking place at a wide multipurpose area at the school that also serves as stalls for the audience during theater performances. These assemblies, which vary in frequency, from weekly during regular periods to daily during periods of wide-school projects, include all students and most school staff. During the assembly analyzed here, the collective task of preparing a theater show called "The Masters" is presented for the first time. Ms Sylvia, the principal (who also is a teacher), has begun by checking how students are doing, moving then quickly into a revision of few of the "seven habits" that are part of a program, The Leader in Me, which the school follows and which is designed to support " $21^{\text {st }}$ century leadership and life skills" (The Leader in Me, n.d.). The revision starts as Ms Sylvia asks, "what is habit number one from the leader in me?" There follow a series of question-answer sequences, where Ms Sylvia is the one who asks, and the students, who raise their hands before they can be chosen, (Figure 3), provide answers if and when chosen.

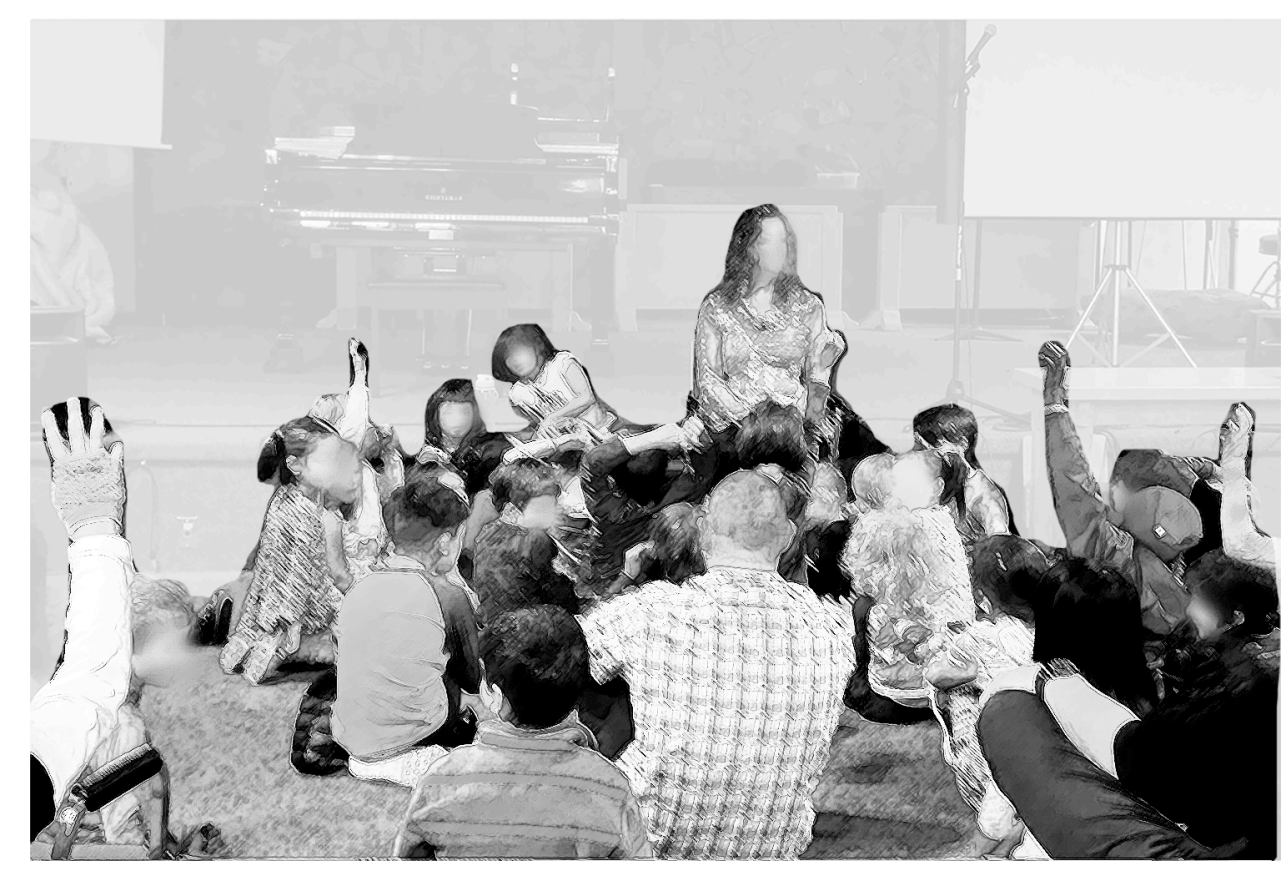

Figure 1: Assembly during which the show The Masters is introduced as a task for the school community.

\section{Excerpt 1}

(MS: Miss Sylvie; K: Kendall; Si: Simon; Ar: Arianna)

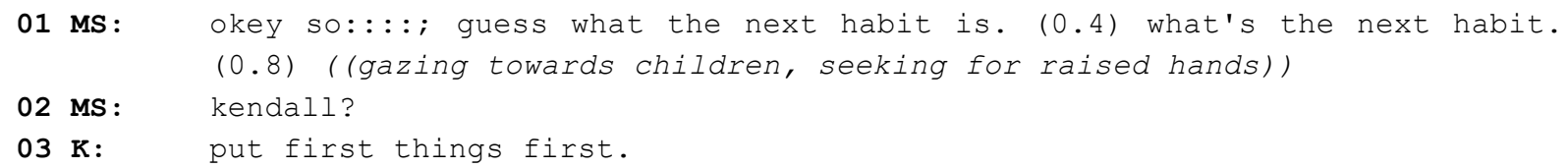




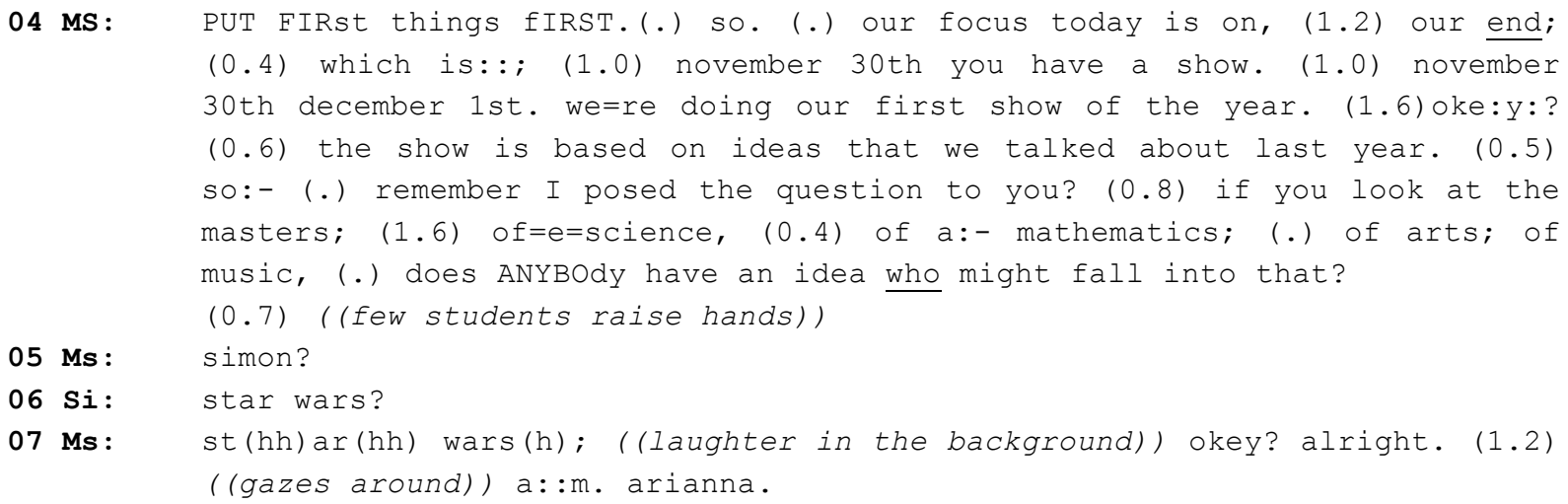

We enter the scene as the group has just gone through the two first habits, ("be proactive," and "begin with an end in mind"), moment in which the "next habit" is requested through a question, and introduced as a task to "guess" (turn 01). Hands are raised and a search begins as the principal gazes across the raised hands, ending the search with the naming of a student, who then takes the turn and provides an answer. Posing and answering a question is thus jointly achieved, teacher (principal) and students enacting a collective ritual common to many school situations in which rights to ask and rights to provide and answer are publicly and visibly organized.

There is then the introduction of a new topic, which comes attached to the students' response by means of the connective "so," and consists in the announcing of what turns out to be the "focus today" (turn 03), emphatically labeled as the particpants' "end" and which is announced to be a "show" that the students will be performing in coming dates. A further connection is made through a reference to something talked "last year," which then is treated by the same speaker as an occasion to pose another question, this time concerning "the masters," namely whether "anyone have an idea who might fall into that."

A search ritual begins again, and a student who has raised his hand is named (turn 05) and pronounces the title of a well-known movie with a raising intonation that suggests questioning rather than answering. In the reception we observe then work making visible that the response is taken up as involving surprise. Ms Sylvie repeats the answer emphatically, with mild laughter inserted in the articulation, and others in the background also laugh. The principal acknowledges the response, "okey? alright." (turn 07) and proceeds to search for a next speaker. The selected student then offers another response, this time naming a famous character of a popular comic strip. In almost identical fashion as in the previous question-answer, the principal again acknowledges the answer with marked emphasis, and then starting the search for a new answer.

The sequence continues like this for a few minutes, during which, in addition to Star Wars and Charlie Brown, students and teachers suggest other names-such as, Mozart, van Gogh, or the Powepuff Girls-all of which are acknowledged. At some point, the recollection stops as the principal instructs teachers and students to divide in groups-led by teachers and/or assistants-to "talk about what a master is" for three minutes. After the group discussion, the groups are gathered again, findings of what a master is are shared, and a new recollection of names begins, leading this time to a written list of names that will, later in the trajectory, serve the families and students for choosing the characters that the children will interpret during the show. 


\section{Reading the episode backwards, and reading it forward}

The sequence, which to educators and educational researchers will be reminiscent to countless other school situations, provides an example of the way learning settings come to be organized as highly structured, jointly and situationally achieved fields of participation. Conversation analysis, which attends to the way turns at talk are organized, provides a usable lenses to examine the course of these achievements. Such an analysis reveals a quite methodic organization that, in studies of classroom discourse, is well known as the Initiation, Response, Evaluation (IRE) or question with the known answer sequence (Mehan, 1979). Here, Ms Sylvie poses a question (Initiation), selects among the hands raised by pointing or naming a student or teacher (teachers and assistants also join the meeting) who provides some response ( $R$ ). The teacher then provides some form of follow up, which in the present setting often takes the form of an acknowledgement, but which elsewhere-and sometimes here too-frequently takes the form of an evaluation (E).

The distinctive character of the sequence as one concerning instruction and knowledgeability is first marked by the nature of the question, which, rather than inquiring about unknown information-as when we ask for directions in a city we don't know well-asks about something for which the inquirer already knows the answer. That the inquirer-in this case Ms. Sylvie-knows the answer, however, is not something we analysts have to infer or find out by making assumptions concerning what goes on inside Ms Sylvie's mind based on the kind of context this is. That the inquirer knows the answer, in fact, is routinely exhibited in the very way in which the posing and the answering of questions is organized in classroom situations (Macbeth, 2003). And this is the case here too, where Ms Sylvie explicitly formulates the question as a consisting of a "guess," and which here consists in naming instances of candidate members for the category "master".

For those of us who, like Ms Sylvie, already know what "a master" means, we know that "Star Wars" or "Charlie Brown"-the two first answers the principal gets from the students-do not fall into the category. As the session continues, other responses are given, including few that indeed fall within the "masters" category, such as "Albert Einstein," "Mozart," or "Van Gogh." In other school settings, such responses may have been marked as incorrect or as correct then and there, by deploying the IRE sequence (e.g., Macbeth, 2004). In this particular setting, however, the "guess" game takes a different character, as all answers are taken up with no explicit evaluation other than the principal's shifts in the emphasis and prosody with which she responds. Instead, the opportunity to learn how to find out the "right" answer is deferred somewhere else, that is, to the group discussion on what a master is, where we do in fact observe a more normative stance in which contributions by students are corrected or revised when not adequate to the "master" definition. By the time the participants gather again, the group manages to produce a list of names that the principal collects and which, built with and by the students, will be the list of characters that the students will be able to choose for creating a script and acting it out in the show.

With the analysis above, we can then perform a reading that takes a retrospective approach, and reifies all that has been described as being evidence that a given context may be invoked to account for the given actions observed. Thus, the description and analyses above provide resources for us researchers and educators to recognize and categorize-after the fact-the current setting as being a particular type of learning context. We can then categorize this school as one in which there is a more learner-centered approach than is typical to more traditional contexts, for here opportunities are given for "integrating everyday knowledge into classroom dialogues to construct intercontextuality" (Wiig, Silseth, \& Erstad, 2017, p. 2), for building those bridges from below rather than "transmitting" them from above. There are opportunities for the children to bring their own everyday perspective, even if it does not align with respect to the canonical notion of "master" being taught. There are also resources to connect with previous learning, as implicit and explicit connections are made between the "having and end in mind" habit and the introduction of the 
show as an "end," or the references to previous discussions about these issues.

Yet, these observations-as legitimate and useful as they are-are drawn taking the retrospective view of those who already know what a "master" means, or what the connection between the second of the seven habits, "to have an end mind," and the introduction/purpose of the show is. Those observations bypass the fact that the interactional materials presented here exist first and foremost as resources for the participants involved, for whom, in the midst of acting-in-setting (to paraphrase Lave's 1988 unit), the retrospective perspective is not yet available. To take the perspective of the learners, to attend to the context not as something somehow already made that contains them but rather as something in the making, a forward reading is required. We can then see the interactions reproduced in Excerpt 1 as a field of mutually involving expectancies and orientations towards projected and project-able next actions (Schegloff, 1989), the precise "meaning" (or consequence) of which cannot be known in advance. As the students raise their hand and take the chance to speak, they always risk to have misheard or misunderstood what the teacher is asking for, or what the agenda of the question really is, for it is precisely that what needs to be discovered. Thus, even when Kendall offers a response about which we may assume she was quite certain about, she could not have anticipated the fact that part of the questions' agenda had been to actually introduce what then became the "focus today", namely introducing the show. It is only after the fact that Kendall can discover this. The same can be said of Simon, who answers a question by posing another question, "star wars?" In every case, attending and becoming sensitive to whatever will come next is crucial for the learners, whose continuity and identity are at stake in that moment of transition, subjected as they are to the consequences of their actions in social interaction.

This is true for the principal too, who, despite working with an "end in mind," can never be sure of what sort of response-if any-she is going to find. This uncertainty stands out, for example, when Ms Sylvie moderately but noticeably bursts in laughter as she acknowledges Simon's response, or when she again exhibits surprise acknowledging Arianna's response, a surprise Ms Sylvie formulates few lines later stating, "this is taking an interesting twist." Thus, although most often the kind of dialogue that is encountered in formal education settings are assumed to build upon an asymmetry of knowledgeability, teacher's position too is one subjected to the inherent uncertainty that characterizes any social situation, in which precise outcomes emerge from the jointirreducibly social-situation (Roth \& Jornet, 2014). In the current episode, we observe instances in which the asymmetry in knowledgeability tilts to the side of the student, such as when, having raised her hand and having been selected to speak, a student states-again with distinctive raising pitch-a name, "Cristin Duncane?" which leads to a sequence of genuine questions by the principal, starting with a prompt "who is she?" all which the student responds fluently, now the one on the know.

At a more general level, the sequence above evidences that and who participants to conversation continuously orient toward the projectability of prior and ongoing actions, so as to be able to produce responses that, most likely-but never absolutely certainly-will be intelligible and therefore coherent for the parties. In entering the "guess" ritual described above, students and teacher engage in the labor of closely monitoring what the other's responses are; not just what they state in words but most finely how those words are delivered in terms of timing, pace, prosody, laughter, and, in sum, all those material and concrete aspects of which actual social situations are made. As part of these, Simon's uncertainty, the principal's joyful surprise, and any other affective expression become inherently intertwined with the signs the participants produce to make visible for each other what type of situation this is they are jointly performing so as to be able to continue participating intelligibly. In that they involve learning to anticipate and become attuned to typical or likely sequences of interaction, conversational sequences such as the one 
described here have important implications with regard to how participants develop distinct learning identities and dispositions that are not necessarily context-bound.

\section{b. Episode 2: Choosing a character}

In the previous section, we examine an episode in which the show "The Masters" is introduced for the first time as a task for the school community. Through the assembly, it becomes clear that for many students the notion "masters" has not yet a clear definition. By the end of the assembly, the participants have jointly produced a formal definition of what a master is and have provided a list of members to the category, that is, a list of masters. The sense the notion "master" will take and the implications it will have for the (learning) lives of the different participants, however, is something that develops with the participant's activities through time and across settings, in the same manner as Russian psychologist L. S. Vygotsky (1987) identified as the "primary result of [his] work" (p. 245) that word meaning develops. Investigating such development involves examining the ways in which attitudes, orientations, and the kind of attentive skills that are highlighted through the analyses above emerge in and through social situations that come to form part of learning trajectories. It is those social situations that are the site and source of the development of individual personal trajectories. There is therefore an inherently pedagogical ${ }^{4}$ character to any social encounter that leads to development or ontogenesis, independently of whether (formal) schooling is involved or not (informal).

To provide empirical content and relevance to the assertion above, in the following, we examine how, in the situated work of choosing and beginning to explore a "master" character, not only are attentional dispositions and orientations shaped, but these can be seen as shaping the participants' personalities and (learning) identities. The episode takes place at Carla's bedroom a weekday in the evening at bedtime, father and daughter semi-recumbent on Carla's bed (Figure 2). The image may at first be reminiscent of a recognizable practice common in literate families in Western societies: bedtime reading. The sheet the father is holding, however, is not a book or a story but a school assignment containing the list of "masters" that was produced during Episode 1 and explaining what the show is about. Another sign that this may not be a usual bedtime story is the fact that a laptop lies open on the bed, a rather modern but increasingly common addition to everyday household landscapes. At a first glance, thus, the scene is difficult to categorize as involving one or another context, thereby suggesting polycontextuality (Engeström, Engeström, \& Kärkkäinen, 1995) or intercontextuality (Leander, 2002) or a mixture of contexts.

\footnotetext{
${ }^{4}$ Here we follow H. Daniels (2001) definition of pedagogy as "forms of social practice which shape and form the cognitive, affective and moral development of individuals" (p. 1).
} 


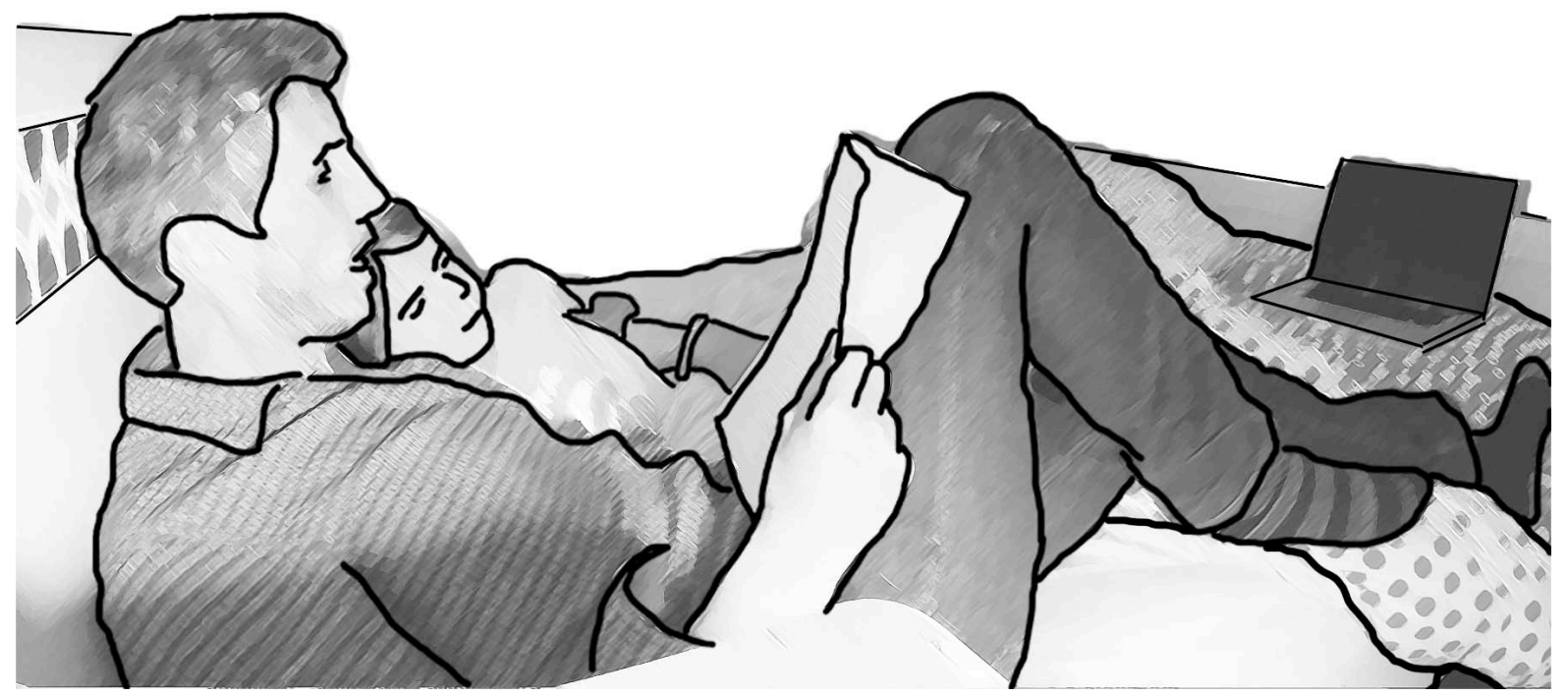

Figure 2. Carla and her father reading a school task at Carla's bedroom.

\section{Excerpt 2a}

(F: Father, C: Carla)

$01 \mathrm{~F}$ : a ver. por dónde estábamos? cuéntame por dónde íbamos.

\{let's see. Where were we? tell me where we were.\}

$02 \mathrm{C}$ : estábamos por aquí ((points over document)) creo.

\{we were over here I think\}

$03 \mathrm{~F}$ : pero qué estaba diciendo; de qué va esto;

\{but what was I saying; what is this about;

$04 \mathrm{C}$ : estabas- que: $\mathrm{m}::$ : you can be whatever you want- ((laughs)),

\{you were- tha:t \}

$05 \mathrm{~F}$ : te lo voy a volver a leer, vale?

\{ am going to read it for you again, okey?\}

06 C: vale.

\{okey.

Excerpt $2 a$ presents a sequence in which the posing and answering of questions again is worked out so as to become an instructional occasion. Father poses a question, and asks where they were (turn 01) and Carla points over the document showing were she "thinks" they were. The answer is then taken up with a "but", an other-initiated conversational repair (Schegloff, 2007) that recycles the question, which now specifies another request: "what is this about?" (turn 03). Carla hesitates, initiating and interrupting talk, and then, shifting to English-they had been speaking Spanish, one of the family's languages-provides a new answer (turn 04): "you can be whatever you want". The father then offers to "read it for [her] again", to which Carla's accepts (turn 06).

\section{Excerpt 2b}

$07 \mathrm{~F}:$ if your child wants to have a little role, =

$08 \mathrm{C}: \quad$ =puede cantar, puede bailar, y puede hacer drama. (lcounting with 


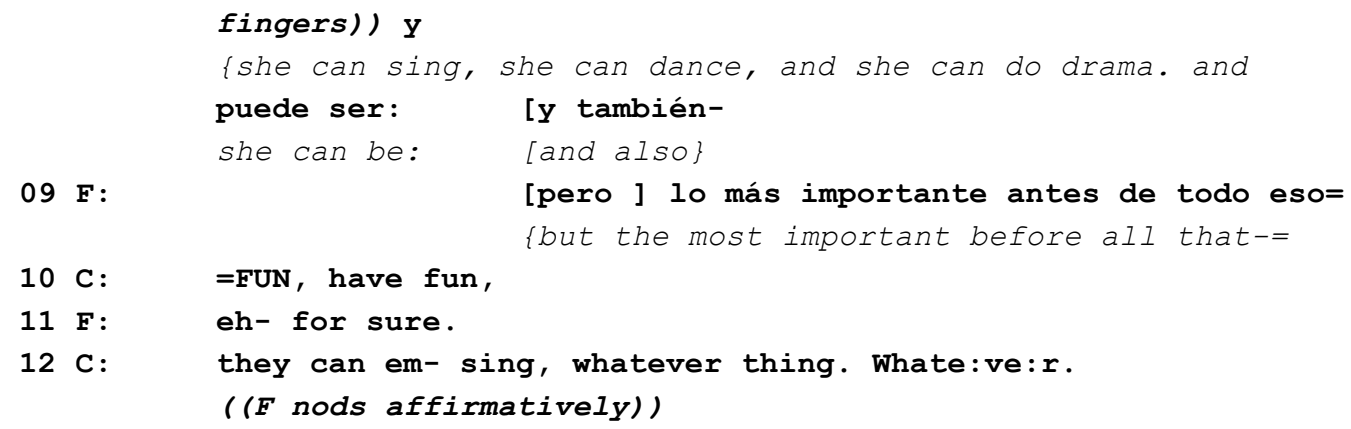

In the turns that follow, as father attempts to re-orient the reading of the school's information sheet, the reading becomes a learning task-this time by means of work initiated by Clara, who now marks the situation as one of guessing work. Thus, father reads from the sheet (Excerpt $2 b$ ), but Carla quickly interrupts, taking over the turn and completing what father may have been about to read (turn 08). There is another interruption as father inserts another "but," and initiates a formulation concerning "the most important before all that," which in turn is interrupted by Carla, who again hurries to complete father's sentence with an emphatic "fun" (turn 10), adding that they can sign whatever, both of which are taken up with an affirmative acknowledgement.

Few turns later, after having read in the sheet that there is a list of masters to choose from, father notes, "you have to choose one ... it's like you gonna be she or he... and you are going to make songs related to that character... You cannot make the poo poo song not because it is something bad, but because the song has to be related to the story". In the same humoristic tone Carla then asks, "what if I were to choose the person who invented toilets? Could I then sing the poo poo song?" Father asserts affirmatively, "Yes, I guess so".

\section{Pedagogy in everyday life, everyday life in pedagogy}

In the episode above, a situation that may first be characterized as bedtime reading soon demands further qualification. In addition to the visual clues observed above, the type of dialogue (Excerpt $1 a-1 b)$ further testifies to the poly- and inter-contextual character of the situation. There is, to begin with, a mixture of languages, Spanish and English coexisting across and even within turns. Most relevant to the problem of learning across settings, there appears to be an instructional orientation in the talk. In fact, if we were to find excerpt 1a "out of its context" and we would not have seen the image in Figure 2, we might have inferred that this was a classroom conversation. For if we attend to the organization of talk in the script alone, we notice the presence of the same recognizable organization of turn-taking that we found in Episode 1.

Through the sequence, it becomes evident that the initial question, although first heard and responded to as in fact asking for a where (location in the text), seeks in fact not information but confirmation of Carla's attention not simply to location, but to relevance, of what "this is about." There is a question, a response, and then the initiation of a repair, which both functions as an evaluation and to further seek a new response. There is a new answer, but instead of an evaluation there is now an invitation to start anew whatever they were in the midst of doing/reading. A "pedagogization" of everyday life at home may be identified in the sequence, where discursive practices typical of schooling are recognizable in the way that the father-daughter interactions are organized. Less common of but also present in school settings, there is in this sequence a sense of humor. Thus, in the lines that follow excerpt $2 b$, Carla brings up a funny inference connecting to the observation that they can choose to do "whatever": "oh wait ... can I sing a poo poo song?" 
(turn 13), while singing a silly song and laughing, her father smiling too. Rather than objected or disregarded, however, the funny inference is taken up as yet another instructional occasion.

Further remarks on the intercontextual nature of the situation may be drawn in terms of the kind of objects that are present in the setting, particularly those brought about by digital technology. Thus, as father and daughter go through the names in the list-itself an artifact produced in the school setting-they use the laptop to browse Internet searching for the names, and accessing online encyclopedias and other repositories to gather information about each of the characters. At some point through the browsing, we can observe Carla's exhibition of surprise as she comes to recognize a picture from one of the storybooks she reads at her school (Figure 3 ). It turns out, one of the names in the list is the author of the book, one of which father did not know about before. And again here, all seems to be a mixture of contexts, for it is not only the different contexts that can be made relevant, but also the shift-which we observed in the school setting as well-in which the one assumed to be "less capable" or "unexperienced" one in a teaching-learning situation, becomes the one in the know. Here, at least for a moment it is Carla who informs father about what these storybooks are about or who is the character in the image they are looking at in the laptop's screen.

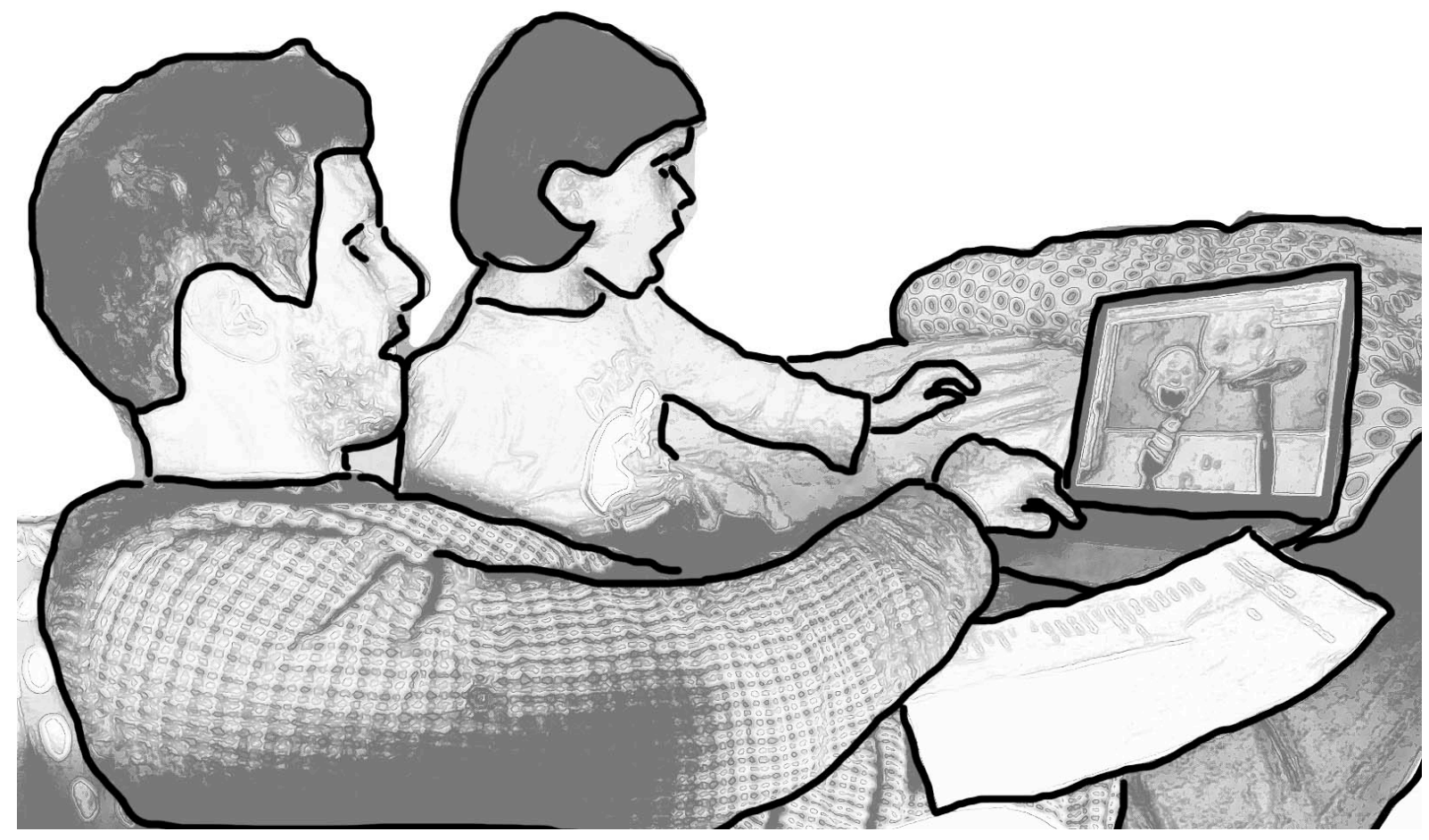

Figure 3. Carla exhibits surprise as she recognizes a storybook she knows from school while they search online for information about one of the names in the list.

The observations above serve to draw contrasts between what typically is found in given settings (the school, the bedroom). Yet, finding what of the school is in the home, or what of the home is in the school is an indeterminately debatable question and does not contribute understanding the growth that goes transversally. Attending to that transversal aspect, we observe not a context but an unfolding contexture that exists in and as the participants work to mark the situation as consisting of a more or less predictable (recognizable) context. In that situated work, we observe shifts in the interactional dynamic. This shift can be here observed in the movement from work to 
establish question-answer pairs (turns 01-05), to a guess game involving assertions initiated by one speaker (father) and anticipated and finished by the other (daughter) (turns 07-12). The shift is consequential for the participants' way of further orienting in and learning from the situation. Taking the place of the father who is reading from the school's sheets, Carla acts consequently with respect to a previous event in which the jointly enacted ritual had consisted in marking out and making visible the expectation that Carla is to exhibit that she follows and knows, exhibiting attention to "what this is about." In and through performing the guess ritual here, Carla is precisely demonstrating her understanding that the context is one in which she is to play the guess ritual so as to position herself as being in the known. But, precisely to the same extent, father is also performing work to mark out the situation as this particular context, and in so doing, is acting consequently with Carla's insertions, allowing her to finish them rather than, for example, continue reading, or when he engages with the inference Carla draws to legitimate her "poo poo song." Father too, then, needs to learn and change.

What changes, then, is the relation, and with it, the persons. Carla is being taught to adjust to whatever she perceives father is orienting towards, while father is being taught to orient to whatever he perceives Carla is orienting towards. Father later on will learn from their joint search about the characters in the list, and Carla will be some times in the know. In the irreducible relation of the two, in that unfolding contexture they are in the midst of weaving, both of them are learning and being changed; in the relation, there is space for both to be surprised and to learn precisely because there is not a boundary, not a context that contains them, but their joint relation as the emergence of a given inherently hybrid practice. If we observe a boundary crossing here (between father and daughter), it is not one boundary separating contexts but perhaps one separating turns at conversation. Only that, to make sense of conversation, we cannot separate turns but need to understand each turn in relation to another one.

\section{c. Episode 3: Becoming a master/Becoming a subject}

In the prior section, we highlight how, in orienting to and exhibiting for each other understanding of the unfolding situation-or lack thereof, as in repair-participants both teach and are taught, such that-transcending any fixed contexts-we can find a pedagogical dimension in everyday life interactions that grows transversally rather than as a crossing. In doing so, we also exhibit how those orientations often involve humor, surprise, and other affective aspects of everyday life. Because coming to understand and exhibiting understanding of an ongoing situation always involves bodily and affectively taking part in that very situation, we are not only agentive subjects of but also are subjected to the situations of which we form part. Intellectually growing with regard to any subject matter or concept, such as "master" in the current trajectory also and at the same means growing affectively, and involves growing always in unexpected ways that go beyond any educational goal, what Dewey referred to as collateral learning (1938/1997). In this regard, following learning lives across settings involves attending to the way intellectual and affective dimensions mutually constitute each other as new horizons of possibilities open for the learners, a process that has been referred to as of subjectification (Biesta, 2013; Roth, 2014). In this opening, not only the affects and the understanding develop, but also the imagination-the power of which "lies not in mental representation, nor in a capacity to construct images in advance of their material enactment," but in "the generative impulse of a life that is perpetually pulled along by the hope, promise and expectation of its continuation" (Ingold, 2015, p. 140). Subjectification, then, "is about the appearance ... of a way of being that had no place and no part in the existing order of things" (Biesta, 2013, p. 85).

To illustrate the points above, we look at later moments in Carla's trajectory preparing for the 
show, the first one of which takes place at Carla's home the afternoon following Episode 2, this time at the dining table. Father and daughter retake the task of searching online for information about each of the names in the list, mostly focusing on female characters. Excerpt 4 takes place 20 minutes into the search, having covered several items in the list.

\section{Excerpt 3}

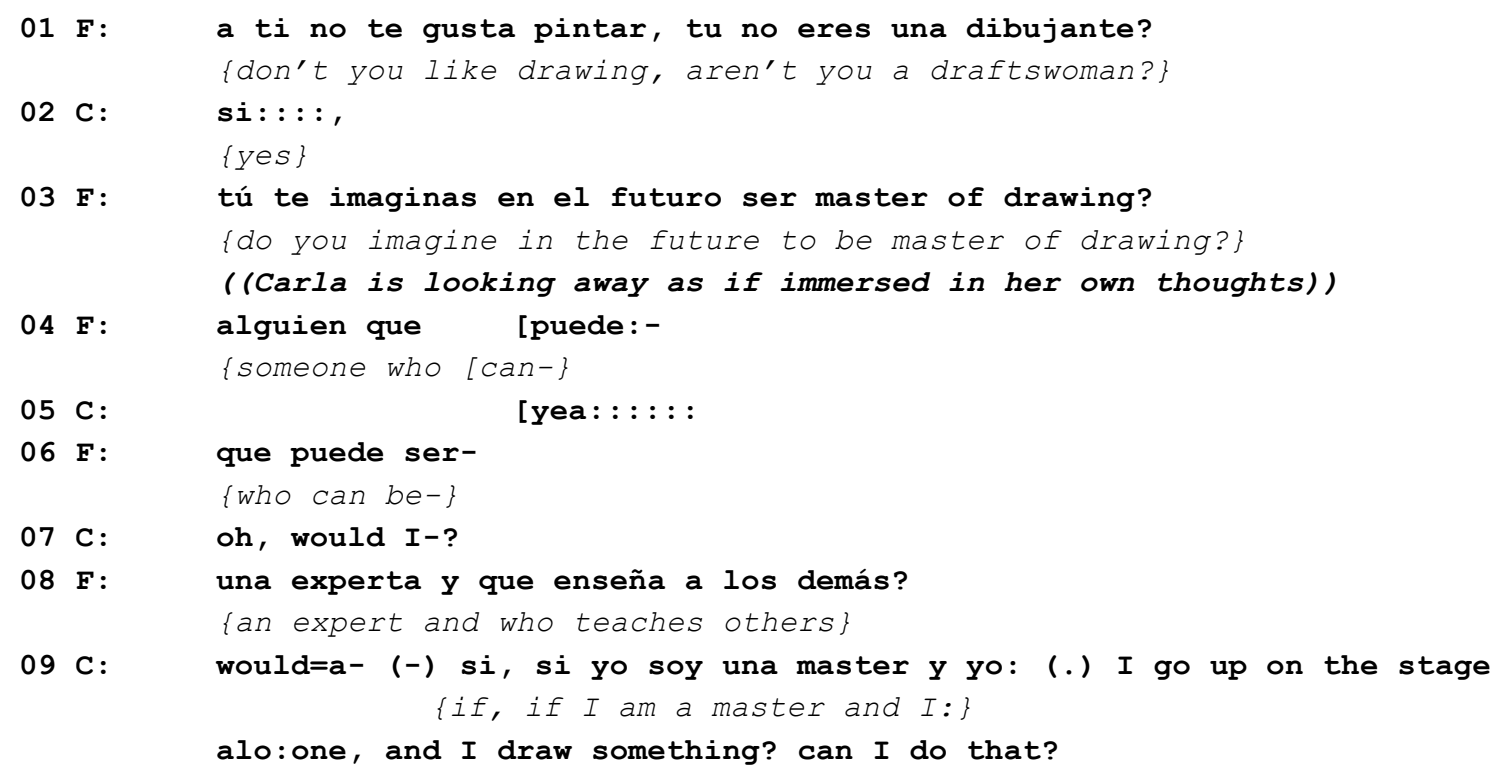

Part of the educational goal of having the school community members participate in the preparation of the show is to help them understand the notion of 'master' not only in terms of a formal definition, but also and perhaps most importantly as a lived and multidimensional concept that, hopefully, will also have an impact in the students' motivation to learn and continue learning. In the sequence transcribed here, an orientation to this goal may be recognized (by those of us who already know about it as premise for the project) in father's invitation to imagine (turns 0106). The invitation is not just formulated, but takes the form of a performance in which the action of imagining is staged out and made visible. As father is formulating the invitation-preceded with a question whether Carla considers herself a draftswoman, to which Carla responds in the positive though visibly doubtful-Carla gazes to the distance. In the midst of father's articulation, she inserts an emphatic "yea" that would seem to report on the seeing of something of which she has been invited to look at. As father seems to be concluding his invitation with a formulation that reminds a formal definition of "master" ("an expert that teaches others"), Carla poses a question, whether it would be possible to "go alone on the stage and draw something" (turn 09).

\section{Subjectification, affect, and imagination}

In the sequence, an invitation to imagine is accepted, and a vision, the seeing of an image, is performed and formulated: Carla going up the stage and drawing, playing the role of Frida Kahlo. As it will turn out, this image-Carla painting over the stage-will eventually take place when. After finally having decided to play the character "Frida Kahlo" in fact having painted one of Kahlo's selfportraits, Carla will go up on stage during the show's presentation and play her character as she paints her self-portrait (Figure 4). Out of the trajectory being described here, an image emerges 
that comes to have direct implications in the way that Carla comes to prepare her part of the script and performance.

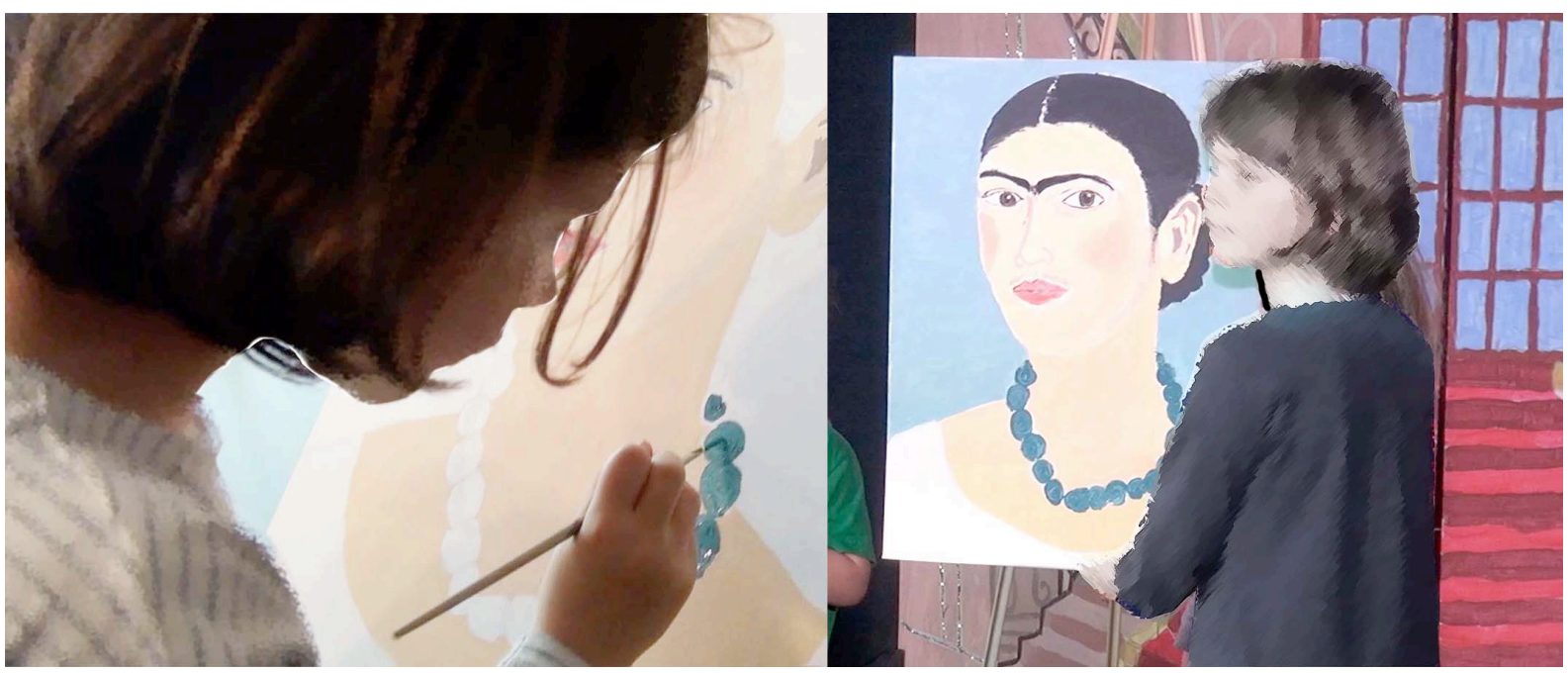

Figure 1: Carla draws a self-portrait as Frida Kahlo (left-side image), which becomes part of her performance (here, right side image, during a rehearsal).

We may now analyze the situation from a perspective that treats contexts as somehow being separated, demarcated by boundaries. Drawing a boundary that would separate father from daughter, we may say that, in inviting Carla to imagine in the terms he does, father lays out or shares a way of looking that somehow Carla "appropriates" or "internalizes," so that she now, too, sees a path. It is in this sense that processes of learning in the broadest sense, whether in formal (the school) or informal (the home, the after school) settings, frequently are recognized as involving a process of socialization. The child, the younger or less experienced participant, acquires modes of being that exist in the surrounding culture, a cultural context that is internalized.

By contrast, when culture, i.e., context, is approached as being something internal to the relation, it is not outside or alien to the person: it is neither outside nor inside, for it is not about location but about history and duration. From that view, culture is father-and-Carla-relating-to-each-other, the actual labor (work) of doing so, and there is no external context. Context unfolds as the relation unfolds, and because the relation is material through and through, it takes concrete shapes and directions as events occur that both build on what already has gone and point towards what yet is not. Culture is from this view not about established regions and crossings as much as it is about modes of opening horizons. And these horizons, as the excerpt above illustrates, are not purely intellectual, but bring with them affective hues and sensitizations. In Carla's making visible that she is seeing something (turn 05), thus, she exhibits being moved-thereby marking the emotional content of what father and daughter are making together. Father, too, has offered the invitation to imagine with marked emphasis, and a sense of excitement and enthusiasm is perceivable as Carla articulates the image of herself drawing on the stage.

A consequentiality can be traced not across but along the work of marking out contexts of interaction. Thus, when father poses the question in turn 01 whether Carla likes painting, he is not just appealing to Carla's prior experience, or to Carlas' everyday knowledge, but also to a "context" that is being constituted then and there and without which posing that question would make no sense. It is as foreground in the background of already 20 minutes surfing the net for the third day in a raw, checking out names of "masters" that had been introduced at an assembly and further talked about in the classroom, in the playground with peers, and in the bedroom. It is a foreground against a background of a shared history in which Carla is known as being particularly fond of 
drawing, having been recognized as such by her parents, teachers, and peers throughout the year we recorded. It is only from that position that father's question in turn 01 makes sense insituation.

To account for this process of history accruing to persons, to ways of relating to and being addressed by others, the notion of subjectification may be more appropriated. Biesta (2013) indeed distinguishes between socialization "which is about the ways in which, through education, individuals become part of existing orders and traditions" and subjectification "which is about ways of being that are not entirely determined by existing orders and traditions" (p. 18). In subjectification, then, there is appeal to the formation of persons not as products of pre-existing contexts but as productive creatures that grow along production. In this reflexive relation of social practice, not just images, but feelings, affects, and, in sum, personalities are generated.

\section{Discussion}

The realization that cultural context is not simply an external factor to what it means to learn and develop has huge implications for the way educational research is to understand how people, and particularly young people, learn in and across contexts in the digital age. Adding to a growing literature concerned on this issue, the purpose of this study has been to explore the research insights and venues that a learning lives perspective may bring when emphasis is made in the notion of life itself as guiding principle. At the outset of the study, we ask, what analytical categories and units may be consistent with an approach that takes life processes rather than settings or contexts as the starting point? What types of insights may those categories lead to? And how may the latter complement or expand existing situative and sociocultural literature? Throughout the analyses, we have provided answers to these questions, exhibiting specific forms of analysis and categories, and contrasting the insights those give with the ones one arrives at through the notions of contexts and boundaries. We have exhibited how a focus on life demands a forward reading, and how, through that reading, everyday life is discovered as a form of pedagogy, one as part of which we become subjects of and subject to, both active agents and passive sufferers of a learning life that transforms us and the settings as part of which we grow. In doing so, our aim is not to disregard the idea of boundary, boundary crossing, or any other of the notions mobilized from the literature, nor it is our goal to argue that learning lives is the right substitute. Our goal is to challenge and explore the limits and ways of expanding of those other notions, and,exhibit research avenues and insights that might otherwise remain unexplored.

In this section, we summarize our answers by means of two overarching themes: (a) the question that we borrowed from Edwards (2009) and which opened the article, concerning what happens when everyday life becomes the context, and (b) the question of categories that may be arrived to and mobilized when studying trajectories from the learning lives perspective.

\section{a. Life as context}

"Contexts of school-related discourse are not static backgrounds; rather, contexts are produced, negotiated, and hybridized within the flow of dialogue" (Leander, 2001, p. 637)

We open our discussion with a quotation that synthesizes the spirit of much of current situative and sociocultural research on the problem of learning across settings. As the quotation states, contexts are not static backgrounds but are "produced, negotiated and hybridized within the flow of dialogue." In order to deal with this emergent nature of context in dialogue, notions such as 
hybridized intercontextuality (Leander, 2001) have been proposed. We may thus say of a given setting or situation that it is a hybrid of multiple contexts: it may involve elements characteristic of school praxis, but also exhibit elements characteristic of, for example, a home context. In doing so, we take recourse to our competence as informed educators and analysts concerning which types of activities characterize which types of settings. We may then set intercontextuality as a goal for current educational efforts to make school learning more relevant to everyday life (and vice-versa), so that research may focus on how to better inform educators on how to better "create intercontextuality" in and through classroom dialogue (Wiig, Silseth, \& Erstad, 2017). What the notion intercontextuality marks here is more an educational interest and concern for creating and expanding opportunities for learning in school and outside of it. And, as much as that interest is laudable and indeed necessary, it is also important to note that it is a concern that takes a retrospective reading of contexts, as already known classes.

A different-though not disconnected-research interest takes as starting point the perspective of the learners, who, in the conduct of their everyday life, may have very different orientations than those the notion intercontextuality signals. From the perspective of people engaged in the situated work of living, the issue of context is hybrid not so much in the sense of being a mixture of contexts, but in the sense that it remains always an open issue. The transition from the noun "context" to the verb contextualizing has in this sense been introduced to mark the fact that contexts are made and therefore emergent in and through social interactions (van Oers, 1998). The verb thus introduced marks a different interest, one on ontogeny: on how, in (the work of) making and marking their life contexts, people make themselves. It is with this interest and spirit that we have approached the learning trajectory described above. The excerpts and detailed analyses of moment-to-moment interaction show the extent to which the defining and constitutive features of a given setting exist in and as the material and performative accomplishment of joint action. And, most importantly, their constitutive character is ought to and only adequately accountable by attending to the perspective of the learners who are intellectually, emotionally, and pragmatically involved in the making.

The empirical case presented in this study offers a look at a way of schooling that is becoming more and more common and which attempts to reach beyond the classroom, engaging the whole school community, and beyond the school itself, reaching out into the home and other everyday settings. The addition or rather implication of digital technologies into this landscape further expands the reach of the ways in which schooling, as well as learning outside of school, is being transformed. This has led to what has been referred to as a pedagogization or didactization of everyday life, terms "meant to raise some critical remarks about how school practices, disciplines, and knowledge associated with school may become a part of, and even colonise, all spheres of life and work ... seen as a consequence of the dominance of neoliberalism" (Erstad et al., 2016, p. 6). On the other side of the coin, we may also find a prevalent preoccupation in educational literature to better understand how prior experiences from everyday life can be brought to bear and matter for learning in classrooms (Wiig, Silseth, \& Erstad, 2016). In our analyses, however, we have shown that, in every instance that may have been categorized as either school-like or as everydaylike, there was hybridization through and through: we observed the everyday in the school as much as we observed the school in the everyday. We show how, by attending to and following what participants themselves orient to and follow, the relevant distinctions are not those of school and out of school, even when it may still be possible to find recurrent forms of relations differently occurring in the school and in the home. From the perspective of the learners, what matters is that every distinction, if it becomes relevant and makes a difference, it also is character-forming: it teaches even if the content of what is learned is not what was meant to be taught, and it teaches something to all, not just to "students". A learning lives perspective, therefore, demands an open orientation to the types of pedagogies and learning venues that may emerge with digital 
technologies, attending to how new and emerging practices unfold as self-organizing forces in their own right. If typical patterns of relating are important to be able to categorize and contrast, an attention to emerging fields of organization allows for theorizing and organizing new learning practices without reproducing old schemes and expectations, allowing the unknown show itself for us, just as for Carla and her father, a way of performing a character emerged without any of them having been able to anticipate in an absolute way.

\section{b. Learning situations, events, experiences, histories}

Through the argument and analyses presented in this paper, we have critiqued the classical notion of context and have pointed out ways in which current attempts to explain learning across settings from a sociocultural and situative perspective still retain some of the ontological premises associated to it. We argue that, whereas contexts as containers, as settings or locations with already known and well-defined sets of (e.g., schooling) practices, are useful for categorizing and contrasting recurrent dimensions of learning cultures, a learning lives perspective requires ways of segmenting learning not cross-sectionally but transversally, in the durational and open-ended direction that actual learning lives take. Not contexts or settings, but lived-through situations, events, experiences, and histories then become the adequate analytical units that mark or punctuate lives, so that biographies can be collected and told.

In reading learning episodes forward, as we did in our analyses, we come to attend and appreciate the sort of situated concerns in which participants get involved, not only intellectually, but also practically and affectively. As participants are engaged in doing and living, an inherent orientation to what may come next is pervasive, as well as the possibility to bring the past to bear in the present. Researchers have come to examine these space-time configurations in terms of chronotopes, which "can be seen as typical patterns of organization of and across activities in space and time" (Kumpulainen, 2014, p. 56). To this, the findings and arguments presented here add an attention to how organization also and inherently is radically atypical and imaginative in nature, such that not even the most experienced teachers can fully predict what comes next and what that "next" will bring them into, how they will feel, think, or act. Attentive imagination seems to be crucial if individuals are to grow and develop, making explicit a dialectical relation between continuity and transformation. In fact, IRE sequences such as the one presented in our analyses are so pervasive, in part, precisely because they share "the important twin features of being context-free and capable of extraordinary context-sensitivity" (Sacks, Schegloff, \& Jefferson, 1974, p. 699). That is, in the situated, contingent and material work of organizing talk-in-interaction, people engaged in conversation are both enacting a practice that is universally valid and typical within a wider culture, and at the same time, is designed (in the sense of immanently organized) so as to be able to address the specific context of the situation, which is open ended and futureoriented in nature.

An interest in "typical patterns of organization" must bring with it an interest in the formation of habits. In this regard, the classical notion of context is useful only in that it makes salient the fact that, during social situations, people orient to and make visible for each other the type of cultural situations they are taking part of, so that it becomes possible to generate expectations and anticipations and coherently participate in the organization of everyday life and experience (Goffman, 1974). But it is habit, which "covers the formation of attitudes, attitudes that are emotional and intellectual ... our basic sensitivities and ways of meeting and responding to all the conditions which we meet in living" (p. 35), is the fundamental category underlying this capacity to meaningfully participate in social life. Context then cannot adequately account for the formation of 
habits-at least not for those that characterize human cultural relations ${ }^{5}$-for, for any context to be of significance from the learners' perspective and thereby to affect her so as to change her, it needs to already be part of the learner's world, and not a world at the other side of some boundary that first needs to be crossed.

To account for the formation of habits, Dewey introduced the notion of situation, which "is not a single object or event or set of objects and events. For we never experience nor form judgments about objects and events in isolation, but only in connection with a contextual whole" (p. 66). Unlike contexts, situations are not spatial but durational. That is why Merleau-Ponty (1945/2002) writes of the experience of the body's spatiality, which is, the living way of relating to space, "appears to me as an attitude directed towards a certain existing or possible task ... its spatiality is not, like that of external objects ... a spatiality of position, but a spatiality of situation" (pp. 114115). Situations, and experiences thereof, are the stuff of which life stories are made up: it is this or that experience-that time Carla was reading that book at school, that other time she saw the book through a screen in her bedroom-which, after the fact, leads to the formation of a person's (learning) habits. As part of those habits, there will emerge and be established habitual ways of framing oneself and being framed by others as a particular type of learner across different setting, leading to particular learning identities, like Carla, who becomes the draftswoman in the making that once played she was Frida Kahlo. Situations, not contexts, add up to a person's life and world: "the statement that individuals live in a world means, in the concrete, that they live in a series of situations" (Dewey, 1938p. 43). In this article, we have referred to the notion of subjectification as a means to address the way people both actively engage, but also and at the same time passively undergo and are changed by participating in social situations. In the context of an interest to digitalization, a focus on how different ways of subjectification and of digital learning identities (Erstad, 2013) emerge along with new "typical patterns of organization" of participation should prove productive and complement our joint task of developing situative and sociocultural accounts of learning and practice.

\section{Acknowledgments}

The research presented in this article is made possible by a grant by the Norwegian Research Council, grant number 240246. We thank Hong-Nguyen (Gwen) Nguyen and Isabel Antonini for their assistance in parts of the data collection, Wolff-Michael Roth for his support in planning the logistic and ethics requirements for the data collection, and David Socha for his generous and disinterested provision of video-recording equipment.

\section{References}

Akkerman, S F., \& Bakker, A. (2011). Boundary crossing and boundary objects. Review of Educational Research, 81(2), 132-169.

Barron, B. (2004). Learning ecologies for technological fluency: Gender and experience differences. Journal of Educational Computing Research, 31(1), 1-36.

Bateson, G. (1972). Steps to an ecology of mind: Collected essays in anthropology, psychiatry, evolution, and epistemology. Chicago, IL: University of Chicago Press.

\footnotetext{
${ }^{5}$ Of course, discrete stimuli can be related to discrete responses, just like a sound can be related to the salibating of a dog in a Pavlonian experiment. Yet, it has been long established that Stimulus-Response schemes cannot adequately account for human psyche (Dewey, 1896; Vygotsky, 1997).
} 
Beach, K. (1999). Chapter 4: Consequential transitions: A sociocultural expedition beyond transfer in education. Review of Research in Education, 1999, 24, 101-139.

Biesta, G. (2013). The beautiful risk of education. Abingdon, UK: Routledge.

Bronkhorst, L. H., \& Akkerman, S. F. (2016). At the boundary of school: Continuity and discontinuity in learning across contexts. Educational Research Review, 19, 18-35.

Cole, M. (1996). Cultural psychology. A once and future discipline. Cambridge, MA: The Belknap Press of Harvard University Press.

Cole, M. (2003). Culture and cognitive science. Outlines, 1, 3-15.

Daniels, H. (2001). Vygotsky and pedagogy. London, UK: RoutledgeFalmer.

Dewey, J. (1896). The reflex arc concept in psychology. The Psychological Review, 3(4), 357-370.

Dewey, J. (1938). Logic. The theory of inquiry. New York, NY: Henry Holt and Company.

Dewey, J. (1997). Experience and education. New York, NY: Touchstone. Originally published in 1938

Dewey, J., \& Bentley, A. F. (1999). Knowing and the known. In R. Handy \& E. E. Hardwood, Useful procedures of inquiry (pp. 97-209). Great Barrington, MA: Behavioral Research Council. (First published in 1949)

Edwards, R. (2009). Introduction: Life as a learning context? In R. Edwards, G. Biesta, \& M. Thorpe (Eds.), Rethinking contexts for learning and teaching. Communities, activities and networks (pp. 1-13). London, UK: Routledge.

Engeström, Y., Engeström, R., \& Kärkkäinen, M. (1995). Polycontextuality and boundary crossing in expert cognition: Learning and problem solving in complex work activities. Learning and Instruction, 5, 319-336.

Erstad, O. (2012). The learning lives of digital youth-beyond the formal and informal. Oxford Review of Education, 38(1), 25-43.

Erstad, O. (2013). Digital learning lives. New York: NY. Peter Lang Publishing.

Erstad, O., Kumpulainen, K., Mäkitalo, A., Schrøder, K. C., Pruulmann-Vengerfeldt, P., \& Jóhannsdóttir, T. (2016). Tracing learning experiences within and across contexts. A Nordic approach. In O. Erstad, K. Kumpulainen, A. Mäkitalo, K. C. Schrøder, P. PruulmannVengerfeldt, \& T. Jóhannsdóttir (Eds.), Learning across contexts in the knowledge society (pp. 1-14). Rotterdam, NL: Sense Publishers.

Greeno, J. G. (1997). Response: On claims that answer the wrong questions. Educational Researcher, 26(1), 5-17.

Goffman, E. (1974). Frame analysis. An essay on the organization of experience. New York: Harper \& Row.

Ingold, T. (2011). Being alive: Essays on movement, knowledge and description. London, UK: Routledge.

Ingold, T. (2013). Making: Anthropology, archeology, art and architecture. London, UK: Routledge.

Ingold, T. (2015). The life of lines. London: Routledge.

Jordan, B., \& Henderson, A. (1995). Interaction analysis: Foundations and practice. Journal of the Learning Sciences, 4, 39-103. 
Jornet, A., \& Roth, W-M. (2018). Imagining design: Transitive and intransitive dimensions. Design Studies, 56, 28-53.

Jornet, A., Roth, W-M., \& Krange, I. (2016). A transactional approach to transfer episodes. Journal of the Learning Sciences, 25(2), 285-330. DOI:10.1080/10508406.2016.1147449

Kumpulainen, K., \& Sefton-Green, J. (2014). What is connected learning and how to research it? International Journal of Learning and Media, 4(2), 7-18.

Kumpulainen, K., Mikkola, A., \& Jaatinen, A-M. (2014). The chronotopes of technology-mediated creative learning practices in an elementary school community. Learning, Media and Technology, 39, 53-74.

Lave, J. (1988). Cognition in practice. Cambridge, UK: Cambridge University Press.

Lave, J., \& Wenger, E. (1991). Situated learning: Legitimate peripheral participation. Cambridge, UK: Cambridge University Press.

Leander, K. M. (2001). "This is our freedom bus going home right now": Producing and hybridizing space time contexts in pedagogical discourse. Journal of Literacy Research, 33, 637-679.

Macbeth, D. (2003). Hugh Mehan's Learning Lessons reconsidered: On the differences between the naturalistic and critical analysis of classroom discourse. American Educational Research Journal, 40, 239-280.

Macbeth, D. (2004). The relevance of repair for classroom correction. Language in Society, 33, 703-736.

McDermott, R. P. (1980). Profile: Ray L. Birdwhistell. Kinesis Report, 2(3), 1-4, 14-16.

McDermott, R. P. (1993). The acquisition of a child by a learning disability. In S. Chaiklin \& J. Lave (Eds.), Understanding practice: Perspectives on activity and context (pp. 269-305). Cambridge, UK: Cambridge University Press.

McDermott, R. P., Gospodinoff, K., \& Aron, J. (1978). Criteria for an ethnographically adequate description of concerted activities and their contexts. Semiotica, 24(3/4), 245-275.

Mehan, H. (1979). "What time is it, Denise?": Asking known information questions in classroom discourse. Theory into practice, 18(4), 285-294.

Merleau-Ponty, M. (2002). Phenomenology of perception. London: Routledge. Original published in French in 1945

Reed, S. K. (2012). Learning by mapping across situations. Journal of the Learning Sciences, 21, 353-398.

Roth, S., \& Erstad, O. (2016). Positional identities in educational transitions: Connecting contemporary and future trajectories among multiethnic girls. Ethnography and Education, $11,57-73$.

Roth, W-M. (2014). Rules of bending, bending the rules: The geometry of electrical conduit bending in college and workplace. Educational Studies in Mathematics, 86, 177-192.

Roth, W-M., \& Jornet, A. (2014). Towards a theory of experience. Science Education, 98, 106-126.

Roth, W-M., \& Jornet, A. (2018). From object-oriented to fluid ontology: A case study of the materiality of design work in agile software development. Computer Supported Cooperative Work, 27, 37-75.

Schegloff, E. (1989). Reflections on language, development, and the interactional character of talk- 
in-interaction. In M. H. Bornstein, \& J.S. Bruner (Eds.), Interaction in Human Development (pp. 139-153). Hillsdale, NJ: Lawrence Erlbaum Assoc.

Schegloff, E. A. (1997). Whose text? Whose context? Discourse \& Society, 8, 165-187.

Sefton-Green, J., \& Erstad, O. (2017). Researching "learning lives"-a new agenda for learning, media and technology. Learning, Media and Technology, 42, 246-250.

Sfard, A. (1998). On two metaphors for learning and the dangers of choosing just one. Educational Researcher, 27(2), 4-13.

The Leader in Me (n.d.). A whole school transformation process. Retrieved from http://www.theleaderinme.org/what-is-the-leader-in-me/

Tuomi-Gröhn, T., \& Engeström, Y. (Eds.). (2003). Between school and work: New perspectives on transfer and boundary-crossing. Amsterdam: Pergamon.

Turner, J. C., \& Patrick, H. (2004). Motivational influences on student participation in classroom learning activities. Teachers College Record, 106, 1759-1785.

Van Oers, B. (1998). From context to contextualizing. Learning and Instruction, 8(6), 473-488.

Vygotsky, L. S. (1987). The collected works of L. S. Vygotsky, vol. 1: Problems of general psychology. New York: Springer.

Vygotsky, L. S. (1997). The collected works of L. S. Vygotsky, vol. 3: Problems of the theory and history of psychology. New York: Springer.

Wiig, C., Silseth, K., \& Erstad, O. (2017). Creating intercontextuality in students trajectories. Opportunities and difficulties. Language and Education, 32(1), 43-59. 